\title{
Arbor
}

\section{Apuntes sobre la Librería de Cámara}

$M^{a}$ Luisa López-Vidriero Abello

Arbor CLXIX, 665 (Mayo 2001), 287-295 pp.

Yo Ilustre hija de Philipo el Grande Que el quinto a España fue de los Philipos,

De carlos por la gran munificencia A ser del orbe la primera aspiro.

No es frecuente que las bibliotecas tomen la palabra. Incluso como licencia poética, el que el ámbito del silencio se decida a hablar, debe considerarse algo excepcional. Sin embargo, al iniciarse el mes de diciembre de 1764, la Real Biblioteca es la encargada de pronunciar el discurso encomiástico con el que el Palacio Nuevo recibe al Rey Carlos III ${ }^{1}$.

Superviviente del incendio que destruye el Alcázar en la Navidad de 1734, la Real Biblioteca, que se reivindica hija de Felipe. V, es, por la composición de sus fondos bibliográficos, el enlace de Austrias y Borbones y se ha convertido en el mejor testigo del profundo cambio que la nueva Casa Real ha dado al sentido de la cultura escrita en España.

Los fondos de incautación del partido austracista - los libros del Duque de Terranova, los del Marqués de Mondéjar, las librerías de Folch y Cardona, arzobispo de Valencia y la del Duque de Ucedase han unido a los fondos reales procedentes de la Torre Alta del Alcázar y a los libros que el Rey Felipe V se ha traido de Francia. Juntos, formando un conjunto que aúna procedencias reales de las dos Casas y nobiliarias, los libros comparten el espacio que Teodoro Ardemans 
acondiciona, en un pasadizo anejo al Alcázar, en 1711. Un edificio de tres plantas, fachada de soportales con arcos de medio punto, decoración con figuras de escritores y amueblada con armarios finos, que se abre en $1712^{2}$.

Hierro y mármol, sólo, combinados contra el poder del tiempo y el olvido, son las bases del actual Palacio del Rey. Ni duro roble ni cedro peregrino. Nada que pueda volver a desaparecer consumido por el fuego. El oro que hace resplandecer los jaspes en muros, cornisas, bóvedas y frisos se añade, como expresión de esplendor, a una marmórea voluntad de permanencia. Dentro de este recinto, ejecutado con el propósito de durar para siempre, se encuentra otra colección de libros impresos y manuscritos. Son la que los Reyes consideran suyos particulares. Los que por razones de Estado, de afecto o de capricho han decidido tener siempre a su alcance. Forman la Real Biblioteca Particular o de Cámara. A diferencia de la Pública, que como institución pública necesita formalizar su creación con un documento legal, la Privada, como bien personal de los Reyes, no ha necesitado ningún acto administrativo que la justifique.

Tras una obligada estancia en el Buen Retiro, donde se alojaron los libros mientras duraron las obras, finalizadas en 1761 , se encuentran ahora, como el Rey, aposentados en este soberbio edificio que «sobre una colina edificado/ goza de ayres más puros y mas limpios».

$\mathrm{Si}$ es Carlos III quien la aloja en el Palacio Nuevo, es su hijo Carlos IV quien la instala en un recinto específico y diferenciado. La Librería de Cámara ocupará, a partir de este Rey, el lugar que se le destina en el nuevo edificio, planta principal del ala sureste del edificio, el llamado "aumento de San Gil» proyectado por Sabatini. Hablar de la esta Librería obliga a comentar el lugar que ocupa porque el espacial es uno de los elementos más expresivos de la definición de sus funciones ${ }^{3}$.

Elegir un espacio ha de entenderse como un acto de designación. Nunca es una acción gratuita decidir qué lugar se ocupa pero, si esta elección se efectúa dentro de un microcosmos donde el orden tiene una lectura de rango - como es el caso de un recinto destinado a ser escenario y sede de la vida del Rey- la elección espacial se convierte en un acto simbólico de concesión de estado. La ubicación de la Librería de Cámara dentro del Palacio Nuevo traduce las funciones que se le tienen acordadas con relación al Rey y a la Corte. Como en tantas otras cosas en este periodo, se ha seguido el modelo francés para instalarla junto a los cuartos privados del Rey en un espacio lujoso en el que, bajo la protección de los dioses que la custodian desde las 
bóvedas, una colección bibliográfica excepcional de manuscritos, incunables, impresos antiguos y otros materiales, se despliega vestida con caprichosas encuadernaciones.

En 1808 la Librería ocupa doce habitaciones. Fréderic Quilliet al describir para José Bonaparte los cuadros de Palacio hace el recorrido valorando las pinturas y nos permite, así, reconstruirla ${ }^{4}$. Se extiende entre el dormitorio de Carlos IV y el de la Reina y cuatro de sus salas tienen bóvedas decoradas por Bayeu y Maella, frescos de factura correcta, acordes al academicismo imperante. La Historia escribiendo sus memorias sobre el Tiempo, Apolo protegiendo a las Ciencias, La verdadera Gloria y La Virtud Heroica, temas clásicos del repertorio iconográfico ligado al libro y la bibliografía que también inspirarán temas decorativos de cabeceras y viñetas grabadas en los libros ilustrados.

Años más tarde, en 1829, Francisco José Fabre publica la Descripción de las alegorías pintadas en las bóvedas del Real Palacio de Madrid. En el tiempo transcurrido, la Librería de Cámara ha ganado nuevos espacios de igual categoría arquitectónica. El que fuera Dormitorio de Carlos IV en el inventario de Quilliet es ahora parte de la Biblioteca. Themis ducit Magna recuerda su bóveda, a través de los pinceles de Bayeu, para que el Rey tenga constancia de que la Justicia gobierna las grandes acciones. En la testamentaría de Fernando VII, habrá una sala más dedicada a Biblioteca Numismática y otra, la mencionada decimo séptima, en la que se conseva la cartografía. Aparte de los cuadros, detallados ya por Quilliet y entre los que están, entre otras, telas de Velázquez, Tintoretto, Rubens, Durero, Pompeo Battoni, Giaquinto, Teniers, en la testamentaría se tasan más objetos suntuarios que conviven con los libros: esculturas, relojes, muebles, espejos, draperías.

En ese recinto de opulencia y fasto permanecerá la Librería hasta que al morir Fernando VII su viuda, M ${ }^{\mathrm{a}}$ Cristina de Borbón, la somete a un traslado forzoso, y, en aquel momento, degradante. Confinada en el ala noroeste del Palacio, la Biblioteca de Cámara, expresa con este alejamiento del ámbito privado del Rey, el cambio definitivo de mentalidad y el diferente entendimiento del papel de la Corona; en suma la quiebra del Antiguo Régimen y el agotamiento de un concepto de Librería Particular ligado a los principios de la Ilustración española.

La dinámica del tiempo ha jugado, sin embargo, en favor de la Librería y, hoy no podemos sino agradecer que a $\mathrm{M}^{\mathrm{a}}$ Cristina de Borbón .le sobrasen los libros y le faltase el espacio. El ángulo noroeste del 
Palacio es el mejor lugar, desde el punto de vista de la conservación: el más frio, el más resguardado de la luz solar y el que, mirando a la Sierra y a los jardines de Sabatini, está menos expuesto a la contaminación. También hay que subrayar que durante la Restauración, bajo Alfonso XII, Remón Zarco del Valle, Bibliotecario Mayor del Rey, consiguió devolverle, bajo los principios estéticos decimonónicos, el esplendor del que se la había despojado en 1837. En la actualidad, la Real Biblioteca es una de las más hermosas bibliotecas históricas.

Expresión del proyecto ilustrado de los Borbones Mayores, la Librería Particular, consolida durante el reinado de Carlos IV sus funciones como espacio de representación y como depósito de la cultura y el progreso nacionales. Con este rey, formado por su padre en un modelo de educación en el que el libro, material e intelectualmente, ha tenido la mayor importancia, vive la biblioteca el momento de mayor esplendor. Criado en una política libraria ilustrada, como Príncipe de Asturias, Carlos IV ha asistido a los progresos de la imprenta y ha sido testigo de los logros alcanzados gracias al fomento de las artes del libro y al apoyo a la cultura literaria. La Real Biblioteca Particular es producto y testimonio de una educación principesca dirigida por los factotum de la renovación de la enseñanza en España.

El concepto de Rey y de Príncipe han variado profundamente a lo largo de un siglo en el que una Revolución que termina con la Monarquía en Francia, es la fecha que indica el cambio de Época.

$\mathrm{Ni}$ la lectura en el desierto, donde se ingresaba por la Filosofía y se salía por la Teología de la Regia Escurialense, ni la librería o el studiolo de la Torre Alta del Alcázar, formada por Francisco de Rioja para Felipe IV, con sus sobrias encuadernaciones en pergamino, eran modelos que podían asistir al sentido que el libro tiene para el Príncipe en el siglo XVIII ni a las necesidades de representación que exige de su colección libraria ${ }^{5}$. El Rey es ahora el exponente máximo del hombre de gusto y necesita un espacio propio donde enmarcar ese nuevo mundo cultural que le construye ante sus súbditos como el representante de una nueva cultura. Su Biblioteca debe conjugar los valores imperantes: el gusto, el lujo, el cosmopolitismo. Su colección de libros tiene que expresar las premisas en las que se ha apoyado el cambio de la Monarquía ilustrada española: la renovación de la dignidad de la nación en artes, ciencias y letras. La imagen del Rey que ahora se encarga de construir la Biblioteca es la del Monarca que une los valores del mejor del pasado histórico con las inquietudes de un enciclopedismo «políticamente» correcto. 


\section{Apuntes sobre la Librería de Cámara}

Los libros del Rey son una de sus colecciones objetuales y por ello tienen como finalidad escenificar valores de su figura ligados a aspectos suntuarios y de imagen; pero manuscritos e impresos, mapas, grabados o dibujos, son, al mismo tiempo, testimonio, escrito o gráfico, de actuaciones concretas de la Corona española; su objetivo, entonces, es ser y servir de memoria histórica del Estado. Así, la Biblioteca particular funciona como herramienta de propaganda y sirve, como conjunto bibliográfico, para transmitir una determinada imagen intelectual de su figura, porque una selección de libros tiene, en última instancia, la posibilidad de configurar a su posesor.

Las lecturas crean un tipo de propietario ideal; este es un principio que subyace en Bibliotecas como la de Cámara en las que, de forma evidente, una parte del fondo bibliográfico se selecciona porque se considera que es ese, y no otro, el conjunto de libros propios de ella. En la Librería del Rey están las lecturas curriculares, las propias de la «educación del príncipe» según el modelo dieciochesco. Reúne fondos bibliográficos canónicos, que no guardan estrecha relación con elecciones personales, y que responden a la función de representación intelectual del Monarca ilustrado.

Esto explica la coherente formación de una parte del fondo bibliográfico que hoy forma la Real Biblioteca, porque durante un largo periodo del siglo XVIII, la selección bibliográfica fue responsabilidad de la elite intelectual que formaba al Príncipe de Asturias y elegía sus lecturas y de la que se hacía cargo de su Librería de Cámara y decidía qué libros y qué colecciones eran los propios de una biblioteca regia acorde a los principios ilustrados.

Quienes se ocupan de formar las lecturas del Príncipe y de seleccionar los libros para esta Librería Particular son quienes están propiciando la renovación nacional. Son el «milieu» intelectual que actúa junto con el gobierno - a veces también forman parte de él- proponiendo y desarrollando proyectos característicos del dirigismo educativo y cultural de los Reinados de Fernando VI y Carlos III, a los que tan magnificamente sirve la imprenta dieciochesca.

Estos hombres dirigen y trabajan dentro de las fundaciones reales de investigación y estudio trocando los papeles que les proporcionan sus cargos. El Preceptor real o el Bibliotecario real -Pérez Bayer y Mayans y Siscar, por citar dos conspicuos representantes de las nuevas ideas - son grandes implicados en el cambio de los estudios y a la vez personas cercanas -en el caso del manteísta- y al frente -en el del erudito de Oliva- de las colecciones librarias principescas y reales. 
El resultado de todo esto es que el fondo de la Librería de Cámara es un estupendo ejemplo de biblioteca dieciochesca, conectada a las corrientes avanzadas de las ideas europeas. Su carácter enciclopédico recoge todas las disciplinas del momento: historia natural, historia de las costumbres, economía política, oficios, libros de viajes, derecho natural. No está, es evidente, el Contrato social pero no faltan ninguno de los libros de Derecho Natural que Rousseau maneja para escribirlo, como la obra de Emer Vattel que figura entre los libros personales de Carlos IV en los años de Príncipe de Asturias.

Los índices de las librerías de los Infantes, de los Príncipes de Asturias y de la del Rey son los que permiten reconstruir estas colecciones. El Indice la Biblioteca de Carlos III lo realiza el reputado librero madrileño Francisco Manuel de Mena en 1760; en él se registran ochocientas veinticuatro obras. Veintidós años después se le añade un Suplemento al Catálogo de la Libreria que tiene para su Real Uso el Rey Nr. Sr. D. Carlos, en el que su autor, Gabino de Mena, Administrador de la Real Imprenta, refleja el aumento de más de quiniento títulos. Ordenados alfabéticamente y empleando la tinta roja para señalización onomástica, estos catálogos de factura neoclásica, reflejan una librería de 8 cuerpos con 6 estantes por cuerpo. En ella se encuentran ya obras destacadas como el manuscrito iluminado a la acuarela que Alfonso Taccoli ofrece al Rey con las divisas y uniformes de los cuerpos militares de Europa, y que es una fuente imprescindible para estudios de historia militar en el siglo XVIII ${ }^{6}$. Pieza que con la representación de más de dos centenares de figuras uniformadas tiene, como es evidente, un enorme interés iconográfico.

Pero es durante el reinado de Carlos IV cuando la Librería de Cámara consolida la importancia de su contendio. El catálogo general de la Biblioteca lo realiza, entre 1799 y 1801, uno de sus encargados, José Angel Álvarez Navarro. Lo hace siguiendo el orden de las piezas. Están los de la $1^{\mathrm{a}}, 2^{\mathrm{a}}, 3^{\mathrm{a}}$ y $6^{\mathrm{a}}$, y se añade posteriormente el de la $10^{\mathrm{a}}$. Los cuatro volúmenes manuscritos marcan ya la distancia con el que al Rey, su padre, le hicieran los Mena y nos ponen ante una colección libraria particular que hay que contar en miles.

Si durante el Reinado de Carlos III se hacen ingresos importantes, por ejemplo el de los fondos relativos a lenguas indígenas de Celestino Mutis, es con su hijo cuando se incorporan las bibliotecas particulares y los fondos institucionales más destacados. El ingreso de la biblioteca del Conde de Mansilla y la de Francisco de Bruna, Oidor de la Audiencia de Sevilla, amigo personal de Jovellanos, que reúne una magnífica biblioteca de carácter humanístico ${ }^{7}$. 
En 1806, muere el Bibliotecario Real de la Particular, Fernando Scio de San Miguel, un escolapio que, junto a su hermano Felipe, ha servido a la casa desde el Reinado anterior. Pasa entonces a ocuparse de los libros Felix Amat y Pont, abad de San Ildefonso y Arzobispo in partibus de Palmira, confesor real. Hombre importante en la controversia religiosa, regalista y filojansenista es un buen representante de la cultura eclesiástica española renovadora. Su influencia es decisiva para la formación de la colección privada del Rey. La compra de la librería del Conde de Gondomar, el ingreso de los fondos de los Colegios Mayores de Salamanca, Valladolid, los libros de la Secretaría de Gracia y Justicia de Indias -entre los que se encuentran los de Francisco de Zamora, Areche, Juan Bautista Muñoz y los de José Ayala- a raíz de la Real Orden de 20 de febrero de 1807 por la que se afectan los manuscritos de los establecimientos públicos, se producen durante su mandato. La trascendencia de estos ingresos de fondos va más allá de su cuantificación y de su valor material, con ser éste mucho. Creo que lo más importante es el hecho de que se produzca y el sentido que tiene el que sean esas y no otras las colecciones que se incorporan a los libros privados del Rey. Su significación como conjuntos librarios y documentales de hombres de estado, bibliotecas y archivos que son las fuentes de la política internacional y americanista de España es notoria.

La Colección es también en este periodo el testimonio fiel de la labor de la que podemos llamar «Imprenta de las Luces»: Imprenta Real, establecimiento emblemático del de las letras y de la industria del libro, y las particulares de Joaquín Ibarra, Benito Monfort, Antonio Sancha y la de Giambattista Bodoni, el impresor de la Corte de Parma a quien Carlos IV otorga el nombramiento de Impresor Real. En este hecho debemos ver no sólo el afán de juntar las preciosas ediciones que se producen sino la voluntad de que la Librería Particular del Rey sea el depósito que atestigue los progresos tipográficos.

Por los mismos motivos se constituye la Biblioteca en depositaria de una magnífica colección de encuadernaciones. El fomento de las artes del libro pasa por la creación de un taller vinculado a Palacio y de unos empleos de Cámara, en oficios de mano, para quienes se dedican al arte de encuadernar. Aparte de su función representativa, como objeto artístico, las encuadernaciones que salen del Juego de Pelota son la confirmación del progreso de ese oficio que la Corona ha dotado de medios y ha estimulado con becas, y del que ella misma se enorgullece de ser su primera consumidora y su garantía testimonial. 
Hasta la que en la actualidad es Real Biblioteca, un centro de investigación en el que los fondos del patrimonio histórico del Patrimonio Nacional pueden consultarse a través de ordenador y que cuenta con una Sala de Investigadores abierta a todos, la Librería de Cámara fue recogiendo la peculiar impronta de cada uno de los Reinados y supo conservar la riqueza bibliográfica, gráfica y documental que dejaron en ella las aficiones de la Familia Real: la música, el arte, la hípica, la caza o la numismática. Los tres álbumes de dibujos que Salvador Maella confeccionó para Fernando VII, en los que se encuentran grandes piezas del dibujo español desde el siglo XVI hasta el XVIII, las Trazas de El Escorial dibujadas por Juan de Herrera, compradas por Alfonso XIII, las cincuenta y cuatro acuarelas que los monárquicos catalanes regalaron a este Monarca ejecutadas por Anglada Camarasa, Mir, Nonell, Meifren, Rusiñol y Casas entre otros, son parte de un acervo artístico que se inicia con el magnífico repertorio visual de las miniaturas del Libro de Horas de Juana Enríquez, conocido como Libro de Horas de Isabel la Católica. La conocida pasión de Bárbara de Braganza por la música es indesligable de la figura de Farinelli y de uno de los más bellos manuscritos de esta Biblioteca, el de Las fiestas reales. El músico, responsable además de la organización y escenografía de los eventos palaciegos durante el reinado de Fernando VI, describe las que se llevaron a cabo en Aranjuez y en las que la escuadra del Tajo era la gran protagonista.

Desde el interés de Fernando VII por el arte ligatoria, el inicio de la fotografía con Isabel II, hasta el desarrollo industrial de la España de Alfonso XIII, sus fondos, que remontan su antiguedad al siglo XII, con el manuscrito Homiliae in quattuor Evangelios, son el camino que conduce a la reconstrucción del libro y de la lectura en el entorno privado de la Casa Real española durante tres siglos.

\section{Notas}

1 IRIARTe, T. (1764): Al Rey Nuestro Señor en su venida a habitar el Palacio Nuevo. Día 1 de diciembre de 1764. La Real Bibliotheca. RB III/6568 (9).

2 SANChéz Mariana, M. (1996): «La formación del fondo bibliográfico de la Real Biblioteca Pública". El Libro Antiguo Español 3, 265-277.

3 LóPEZ-Vidriero, M. L. (1996): "La Librería de Cámara en el Palacio Nuevo». El Libro Antiguo Español 3, 167-183. NAVAS, J. G., CONDE DE LAS. (1910): Introducción. Catálogos de la Real Bibliotéca: autores-historia, V. I.

4 Quilliet, F. (1808): Description des tableaux du Palais. RB II/3269. 


\section{Apuntes sobre la Librería de Cámara}

5 Checa Cremades, F. (1996): «El lugar de los libros: la Biblioteca de El Escorial». El Libro Antiguo Español 3, 101-112.- SANTIAGo, E. (1996): "Animi medicamentum" La biblioteca de Felipe IV en la torre alta del Alcázar». El Libro Antiguo Español 3, 285-314.

6 TACCOLI, A.: Teatro militare. 1760. RB II/82.

7 López-Vidriero, M. L. (1999): Los libros de Bruna en el Palacio del Rey. 